\title{
Child Soldier: ejemplo de cómo llevar las técnicas del teatro contemporáneo al aula de secundaria
}

\author{
Pablo BALLESTEROS \\ Dpto. Lengua Castellana y Literatura \\ I.E.S. Al-Satt, Algete (Madrid), \\ mandaladu@hotmail.com \\ Juan Pedro LÓPEZ VELASCO \\ ETSI. De Telecomunicación \\ Universidad Politécnica de Madrid \\ jlv@gatv.ssr.upm.es
}

Recibido: octubre 2013

Aceptado: julio 2014

\section{RESUMEN}

Los procesos de creación contemporáneos desde la performance al happening pasando por la instalación o el vídeoarte son los idóneos en el marco de la enseñanza en secundaria y sobre todo en grupos de difícil desempeño y en circunstancias complejas, como las que aquí vamos a presentar. Nuestra propuesta es la defensa de una metodología más abierta y flexible en la enseñanza del Teatro en la actualidad, más cercana a propuestas artísticas contemporáneas. Aquí nos vamos a centrar en los inicios de un proyecto performativo, uno de los momentos más complejos y fascinantes de todo proceso escénico, artístico y didáctico.

Palabras clave: Teatro, educación, proceso creativo, performance, material audiovisual, internet.

\section{Child Soldier: from performance to avant-garde techniques in high-school theatre}

\begin{abstract}
Avant-garde theatre techniques are the most adequate on a secondary education high-school theatre project. The art of performance, happening or videoart are essential in this environment, especially with risky groups. Our proposal is the defense of an open and flexible methodology, based on contemporary experiences, which are more familiar to the student. In this paper, the whole creative process is explained from the beginning to the stage, summarizing the landmarks and emphasizing the tools used, which included audiovisual contents and internet.

Keywords: Theatre, education, creative process, performance, audiovisual contents, internet. Child Soldier: La performance et techniques de theatre contemporain dans le jeu de l'école
\end{abstract}




\section{RÉSUMÉ}

Les processus de création contemporaine de la performance jusqu'au happening, en passant par l'installation o l'art vidéo, sont adaptés au contexte de l'enseignement secondaire et surtout pour des groupes qui ont des circonstances difficiles et complexes, tels que ceux que nous présentons ici. Notre proposition est de défendre une approche plus ouverte et flexible dans l'enseignement du théâtre d'aujourd'hui, pour qu'elle soit plus proche des propositions artistiques contemporaines. Nous allons nous concentrer, ici, sur les débuts d'un projet de performance ; un des moments les plus complexes et fascinants de tout processus scénique, artistique et didactique.

Most-clé: Théâtre, éducation,procédé créatif, performance, contenu audiovisuel, internet.

SUMARIO: 1. Introducción. 2. Contexto de la experiencia. La creación de un espacio y un ambiente escénicos en el aula. 3. La elección de un tema como columna vertebral del proceso creativo. 4. La programación de actividades en el aula basadas en el tema. Los ejercicios teatrales como escenas en bruto. 5. La música y el espacio sonoro en el proceso creativo. 6. Procedimientos para la familiarización, compresión y memorización del texto. 7. La realización de la primera escena y su impacto en la evolución del grupo. 8. La introducción de la tecnología, internet y los materiales audiovisuales para convertir el aula en espacio global. 9. Primeras actuaciones y enfrentamiento con el público. 10. Evolución del grupo hacia la consolidación y el éxito en el marco del teatro escolar. 11. Encuesta final como método de obtener las impresiones del alumno. 12. Conclusiones.13. Agradecimientos. 14. Bibliografía.

\section{INTRODUCCIÓN}

El tema fundamental de este artículo es una propuesta de renovación metodológica en el modo de encauzar la asignatura de Teatro en $3^{\circ}$ ESO o en un taller de teatro llevado a cabo con estudiantes de secundaria. Para esta renovación metodológica se precisa un cambio de visión de la materia en el profesorado. Ese cambio de visión se basa en el mayor conocimiento de las expresiones artísticas, escénicas y tecnológicas contemporáneas y en que su utilización no se halla alejada de las necesidades educativas de los estudiantes, sino que favorecen una libertad creativa que motiva al alumnado de esta materia. Manifestaciones artísticas como la performance, la instalación, el happening, el teatro sensorial, el teatro comunitario, el vídeoarte o la música electrónica no son espacios artísticos incomprensibles para el alumnado. Por el contrario, su libertad creativa, su utilización de la improvisación, su contacto con las nuevas tecnologías y su uso de la autoría colectiva entroncan directamente con la visión del mundo de los estudiantes.

Los objetivos fundamentales de este trabajo son dar herramientas al profesorado para encauzar el taller o la asignatura de Teatro de un modo diferente desde el inicio del proceso. Un objetivo prioritario es cambiar la perspectiva del profesorado en esta materia ante circunstancias adversas: no es relevante si el alumnado memoriza o no textos escritos si no basamos el taller exclusivamente en ellos; no es prioritario el trabajo en casa si se exprime al máximo la cooperación en el aula; la 
disrupción de una parte del alumnado puede transformarse en materia escénica. Esos objetivos van a ser reseñados a lo largo de este artículo.

Partiendo de una metodología basada en la utilización de las aportaciones más destacadas de los principales directores de la historia del teatro contemporáneo y poniéndola a prueba mediante el uso de la investigación-acción pedagógica, este artículo rastrea en su estructura las diez u once fases más importantes de esta experiencia-piloto como invitación a la réplica metodológica de todo lo aquí propuesto.

\section{CONTEXTO DE LA EXPERIENCIA. LA CREACIÓN DE UN ESPACIO Y UN AMBIENTE ESCÉNICOS EN EL AULA}

La experiencia aquí relatada se centra en la optativa de 3ESO en el IES AL SATT de Algete, en la Comunidad de Madrid. A lo largo del curso 2012-2013 hemos trabajado con 23 alumnos, de los cuales 18 habían repetido al menos alguna vez durante su vida académica y en el actual curso 11 se encontraban repitiendo. La mitad de los alumnos provenía del programa de diversificación curricular, programa diseñado para alumnos que ya han repetido en alguna ocasión y que precisan de un trabajo adaptado en grupo más pequeño y con una atención más personalizada. Un sector del grupo tenía un abultado expediente disciplinario debido a numerosos partes e incluso expulsiones.

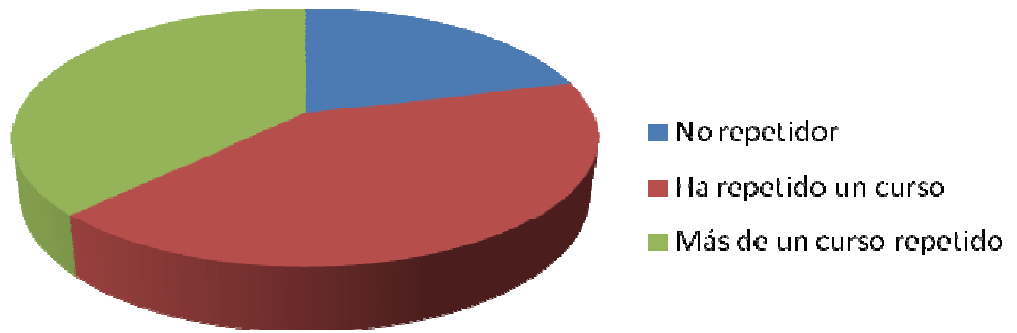

Gráfica 1. Porcentaje de alumnos repetidores

Algunos de los alumnos repetidores del actual curso académico habían cursado ya la optativa de Teatro y manifestaban una elevada insatisfacción y resistencia a la asignatura, a pesar de haberla vuelto a escoger, al parecer porque ninguna de las materias ofrecidas por el centro era de su agrado. Partiendo de esta base, el grupo se embarcó en septiembre en el reto de intentar sacar una compañía de teatro escolar adelante y un proyecto escénico digno y que pudiera ser representado ante un público.

Otra de las circunstancias a la que nos enfrentábamos era la falta de dedicación de tiempo libre y esfuerzo al taller de Teatro, sobre todo por las tardes. Y una elevada resistencia a la memorización de texto, como ellos mismos han confesado repetidamente a lo largo del curso tal y como analizaremos más adelante. 
Una vez reseñado el contexto, lo que aquí pretendemos demostrar es que la creación artística contemporánea, en particular la escénica, tiene en sus procesos creativos una serie de principios metodológicos que son a su vez utilizados por la pedagogía actual. Ambos mundos están entrelazados y cooperan mutuamente. De esta manera, los principios del uso del cuerpo y la libertad para la utilización de textos de diverso origen (Grotowski, 1981) entroncan con la necesidad de trabajo físico, de expresión corporal del alumnado y con su resistencia a aprender textos ajenos de memoria. A su vez, la necesidad de relajar al alumnado al principio del taller y enseñarles a alimentarse del entorno que les rodea en las improvisaciones se relaciona directamente con las estrategias del hatha yoga (Ianatouni, 2009) y el teatro japonés (Oida, 2010) en la expresión contemporánea.

Por lo tanto, ¿qué procedimientos se pueden seguir para materializar esta propuesta? En primer lugar, el aula en la que hemos trabajado, el aula 6, era un aula de música no pensada para hacer teatro. Sin embargo, se debe partir de la base de que cualquier espacio puede ser teatral o escénico. En ese sentido las propuestas más contemporáneas son de especial utilidad. Muchas veces los auditorios o teatros tradicionales son los lugares idóneos para recibir el resultado final de un curso, pero no para ubicar el proceso. La cuestión es hacer teatral el espacio que nos ha tocado. Desde esa perspectiva, transformamos el aula 6 de música en un espacio más libre al retirar las sillas de la parte central del aula. De este modo, los alumnos se vieron obligados a moverse, a participar, desde el inicio, al no encontrarse parapetados en su silla, sentados como meros receptores de una materia. También quedó anulada la posición jerárquica que se suele establecer en el aula entre el profesor y los alumnos con todas las ventajas y riesgos que todo ello pueda implicar. Muy importante es también la creación de una luz especial en el aula, una luz que la distinga de otros espacios del instituto. Nuestra aula 6 de música estaba situada en la planta baja del centro y daba directamente al patio. Bajamos las persianas creando una oscuridad mitigada por luces ligeras provenientes de flexos de colores conectados a los enchufes, linternas o incluso, y con mucho cuidado, velas. Todo ello se acompañó de un iPad conectado a unos altavoces que iban construyendo las músicas, los ruidos y efectos de todo un espacio sonoro ya presente desde el inicio en el aula.

Los alumnos de repente se ven inmersos en un espacio lleno de estímulos sensoriales, que rompe lo cotidiano y les impulsa a reaccionar. Muchas veces la sensación inicial que experimentan es de pérdida de los referentes, ya que no disponen de una silla que marca su territorio o una mesa que los proteja a modo de escudo. Deambulan por un aula de iluminación extracotidiana llena de músicas diferentes. Para sentarse lo tienen que hacer en el suelo y cualquier movimiento o propuesta toca inmediatamente al grupo, lo que le obliga a cambiar de perspectiva y situarse en el objetivo común de un proceso compartido y no individual. Todas estas estrategias siguen los pasos recomendados por la biomecánica (Grotowski, 1981) y por el uso del teatro comunitario (Bidegaín, 2011), para trabajar el teatro 
como espacio para la decisión asamblearia y el impacto social en una comunidad determinada.

\section{LA ELECCIÓN DE UN TEMA COMO COLUMNA VERTEBRAL DEL PROCESO CREATIVO}

Los alumnos más inquietos suelen empezar a hacerse preguntas que apelan a su conocimiento previo de lo que debe ser el teatro: ¿qué obra vamos a representar? ¿Qué personaje voy a interpretar? ¿Dónde está el texto o la historia que vamos a contar? Muchas veces la labor del profesor de teatro contemporáneo y escolar es luchar contra sus estereotipos y prejuicios, luchar contra lo que consideran que es o no teatro. Con frecuencia se divierten con las dinámicas y ejercicios iniciales, pero tienden a verlos como algo lúdico y separado de la obra que van a representar. Sin embargo, nuestra propuesta metodológica es no separar nunca ejercicio o dinámica de posible futura escena. Cualquier evento del taller de teatro, de las clases y los ensayos, es susceptible de formar parte del montaje final. Desde este punto de vista, nos gustaría aclarar que nosotros no defendemos una improvisación a ultranza sin una planificación ni contenidos ni objetivos, lo que ocurre es que nuestro desarrollo del montaje no es esclavo de un texto fijado desde el inicio del proyecto y contemplado desde el principio como el objetivo final de la materia, por sujeto a cambios que este texto se pueda encontrar, sino sujeto a un tema y a un método desglosado en actividades y ejercicios de creación contemporánea directamente relacionados con el tema que queremos tratar. Todo ello significa que el tema debe estar decidido desde el momento en que entramos por primera vez en el aula de Teatro, sobre todo el primer año de trabajo de un grupo. Debe tratarse de un tema amplio y atractivo para los alumnos. Por todo ello, seguimos aquí el orden y las fases de trabajo teatral con un grupo que recomienda Ian Watson (Watson, 1999) en su sistematización del método del colectivo Odin Teatre dirigido por Eugenio Barba (Barba, 1986 y 1992), discípulo del ya muy citado Grotowski. Watson sistematiza el complejo método de Barba partiendo del estudio de su obra y de la observación de ensayos del Odin. Barba había antes generado un cuerpo documental más poético que metodológico y que inspira a Watson en su trabajo. La aportación de Watson es crucial, porque en ella se encuentran descritas las fases del proceso, las actividades concretas, el trabajo con el cuerpo, la voz, el texto, el atrezzo y la fijación de las improvisaciones. Watson desnuda de una vez los entresijos creativos del Odin en los que nos hemos inspirado. Hemos actuado en esta experiencia como una mezcla de Barba y Watson a través de la investigaciónacción.

Nos fue de gran ayuda en este campo el conocimiento y colaboración con el proyecto CaixaEscena de teatro escolar, uno de los certámenes más importantes a nivel nacional desde hace años y uno de los más innovadores y abiertos a nuevas propuestas. CaixaEscena propone para trabajar en el taller de teatro diversos itinerarios que van desde la comedia del arte hasta Shakespeare. Para el curso 
2012-13 había propuesto un nuevo itinerario llamado "Teatro y Guerra". A través de su plataforma online, CaixaEscena es un marco de intercambio, formación y seguimiento de la labor del profesor en el aula. Difunde materiales y guías que puede aprovechar el grupo y seguir el avance de otros grupos a nivel nacional. CaixaEscena culmina con un certamen en directo, en varias comunidades autónomas, que combina talleres de formación con la presentación de una parte de los montajes en un teatro seleccionado por la organización. Ese certamen se denomina Encuentros CaixaEscena y su participación está sujeta a un proceso de selección entre todos los montajes que se presentan.

El nuevo itinerario de Teatro y Guerra se comunicó a todos los profesores inscritos en la plataforma con mucha antelación. Exactamente en julio del 2012. Junto con el itinerario se ofrecían obras que podían adaptarse tales como Historia de un soldado de Stravinsky junto con materiales audiovisuales y propuestas de ejercicio para el aula. A partir de ahí comenzamos nuestra investigación en el tema y las bases de diseño del taller. Al ver diversas versiones de Historia de un soldado empezamos a barajar la importancia de la música en el montaje, la creación de una estructura-base para el proyecto, junto con actividades y ejercicios para el aula. Desde el principio nos dimos cuenta de que el tema era muy atractivo para el alumnado de 3ESO porque aborda aspectos como la muerte, la violencia y entroncaba con montajes nuestros anteriores e intereses artísticos previos. Durante este proceso nos cruzamos con el tema de los niños soldado y vimos la cercanía entre nuestros alumnos y los adolescentes víctimas de esa violencia extrema que es la guerra y los conflictos bélicos. Vimos que la cantidad de material en internet era ingente: imágenes, vídeos, música hip-hop dedicada al tema, documentos y testimonios de niños soldado en la web de Amnistía Internacional, entrevistas a cooperantes internacionales y ex niños soldado... Todo un mundo que nos hizo volver más específico nuestro tema. Nuestra historia de un soldado sería la de un niño soldado. $Y$ un título comenzó a fraguarse en nuestras mentes: CHILD SOLDIER. En inglés, ya que pensábamos abrir el montaje a otras lenguas si fuera posible. Ese abrir el montaje a otras lenguas se basa a la vez en los postulados de Grotowski y Barba, junto con múltiples manifestaciones artísticas de la performance actual. Con ello no se pretende que la comprensión del montaje final se base sólo en lo lingüístico, sino en ver las diversas lenguas como elementos plásticos que interactúan con la parte física y audiovisual. Trabajar en palabras de Mignolo las lenguas en contacto como procesos vitales y no como lenguas puras, mucho más allá de la traducción, vivir las lenguas en el teatro como expresión transnacional de un mundo globalizado (Mignolo, 2003). A partir de ahí empiezan a surgirnos ejercicios que den pie a posibles escenas.

La inscripción del grupo en un certamen como CaixaEscena suele tener un efecto motivador. En primer lugar porque no se trata de un concurso competitivo al uso donde sólo se juzga el montaje final ante un jurado. CaixaEscena sigue y valora el proceso y da una plataforma que empieza a hacer del aula un espacio 
global a través de internet. A esta plataforma se pueden enviar todo tipo de materiales relacionados con el grupo y los profesores implicados pueden colaborar en una serie de foros de intercambio en los que compartir reflexiones, fotos e incluso vídeos. CaixaEscena cuenta con una serie de asesores provenientes del teatro escolar o profesional que orientan y acompañan a los grupos en el proceso. Desde el inicio comunicamos al grupo los motivos para la elección del tema y su participación en el programa citado. También les comentamos la posibilidad de participar en los Encuentros CaixaEscena en el 2013 de modo presencial. Este reto tuvo un efecto positivo en el grupo porque comprendieron mejor la elección del tema y se sintieron partícipes de una aventura, del intento de participar en los mencionados Encuentros.

Dicho esto hemos de aclarar que el certamen no soluciona el trabajo en el aula si el taller no es motivador y está convenientemente dirigido. $\mathrm{Y}$ ahí volvemos al marco del aula 6 de música.

\section{LA PROGRAMACIÓN DE ACTIVIDADES EN EL AULA BASADAS EN EL TEMA. LOS EJERCICIOS TEATRALES COMO ESCENAS EN BRUTO}

Con el tema ya tan claro y un fondo de archivo documental empezamos a plantearnos la estructura de la programación en el aula, las actividades y su organización. Solemos partir de la citada transformación del aula convencional en algo escénico y extracotidiano. La primera tanda de actividades suele ir dirigida a la relajación, las dinámicas de grupo, el aprendizaje de los nombres de los componentes de la compañía, el aumento de la confianza y la sensación de pertenencia a un equipo. Suelen estar combinados con ejercicios básicos de expresión corporal, danza y voz. A su vez, vamos elaborando una encuesta de evaluación de diagnóstico del grupo en la que se recoja su experiencia previa en teatro, danza, música o deportes, sus aficiones, sus intereses y sus motivaciones.

En el caso de este grupo nos encontramos con un elevado número de alumnos sin experiencia previa y que habían caído en la asignatura porque no quedaba otra opción. Un reducido número tenían experiencia previa en danza, gimnasia rítmica, magia, música e incluso teatro. Una minoría. Pocos esperaban algo de la asignatura.

Durante las clases surgía el desconcierto en el taller ya que muchos esperaban estar cómodamente sentados en sus sillas cogiendo apuntes de teoría del teatro a lo sumo o boicoteando todo intento de llevar a cabo una clase convencional. Por el contrario, se encontraban con un aula poco iluminada, en la que podían moverse y en la que se les invitaba a sentarse o tumbarse en el suelo para relajarse, o a correr y saltar al ritmo de tecno radical. Empezaron poco a poco a darse cuenta de que cada ejercicio basado en los principios de la biomecánica (Grotowski, 1981), del hatha yoga (Ianantouni, 2009) o las propuestas metodológicas del actor Yoshi Oida (Oida, 2010) estaba muy meditado y que la clase tenía una cuidada estructura. 
Ellos no conocieron el marco teórico e histórico hasta el final. Hubo pocas resistencias. Pocos alumnos se sentaron en una esquina y manifestaron una oposición frontal al trabajo en Teatro. Incluso los alumnos con un expediente disciplinario más nutrido comenzaron a soltarse en el aula, atraídos sobre todo por las músicas y por un factor clave: la falta de aprendizaje de textos de memoria.

A continuación vamos a abordar uno de los aspectos fundamentales de esta metodología. La asociación de texto verbal o literario con teatro ha podido arruinar muchos intentos de llevar a cabo la compleja labor de sacar adelante un grupo de teatro escolar. La imposición de aprender de memoria un texto instituido por el profesor desde el inicio puede provocar frustración y desmotivación en el alumno. Cada vez son más los profesores que conocen los ejercicios y las dinámicas de grupo del inicio de curso y muchos comienzan el proyecto de una manera envidiable. Pero muchas veces, tras un tiempo de experimentación, buscan un texto y rompen la dinámica del grupo pasando incluso a un marco de enseñanza tradicional y frontal en la búsqueda de la puesta en escena de un texto propuesto. Esta opción suele ser doblemente frustrante porque el alumno ha iniciado un camino lúdico, experimental, tras superar su desconcierto inicial y cuando se ha empezado a sentir cómodo en el grupo, abierto a más propuestas y a colaborar de modo creativo, se ve inmerso en una obra muy fijada, cuyo texto reciben fotocopiado, a la espera de ser memorizado. De repente, se retrocede en el grupo a una enseñanza de décadas anteriores y se pierde el marco creativo en el que se les había introducido. Esta realidad es más frecuente de lo que parece.

Nuestra propuesta es otra: un ejercicio, una dinámica de grupo o una improvisación son en sí mismos escenas del futuro montaje. Como tales deben de ir estando pensadas para que el alumno no sienta que nada de lo que ocurre en el aula es ajeno al proyecto final. Esta directriz metodológica pasa por la desacralización del texto verbal, la no necesidad de contar una historia lineal, la fusión de tendencias escénicas y la importancia del lenguaje del cuerpo, la tecnología y otros métodos de expresión artística. Podemos montar escenas incluso sin palabras. Esa es la premisa que a su vez entronca con la idea fundamental que aquí defendemos: es un principio de la creación escénica contemporánea, en la que el texto es importante pero no detenta el poder. Esta idea se vuelve muy valiosa con un grupo de adolescentes que se niegan, sobre todo al principio, a memorizar texto. Implica muchas veces un salto sin red para el profesor, que debe familiarizarse con el riesgo y debe dejarse sorprender durante el proceso. Experiencias similares como el trabajo de Jim Patterson et al (Patterson, 2006), en el que se confirma esta alternativa como posibilidad de encauzar un taller de teatro, han servido de referencia para la consecución del proyecto.

Dentro de este enfoque teatral, la importancia reside en mayor medida en los objetos que vamos a utilizar en el aula, que en el propio texto de la obra. Con frecuencia se relega para el final el uso del atrezzo o la creación de un ambiente adecuado en un montaje de teatro escolar. Nosotros sostenemos que debe ser a la 
inversa. Los objetos hacen tocar al alumno el tema de la obra y le dan un sentido de realidad. Partimos del trabajo de la biomecánica de Grotowski (Grotowski, 1981), para los que el trabajo del cuerpo y la emoción llevando a cabo acciones en respuesta a objetos, mobiliario o un espacio determinado serían la base de la creación teatral. Nuestros ejercicios en el aula, que se irán convirtiendo poco a poco en futuras escenas, deben basarse en la cuidada selección de los objetos y en la capacidad de éstos para sumergirles en el tema que tratamos. En nuestro caso, tras las relajaciones y los ejercicios de avance por el espacio, de cambio de velocidades, etc. muchas veces les proponíamos trabajar con un objeto muy pensado. Hemos de decir que uno de los objetos con los que comenzamos el proyecto poseía toda la capacidad para ubicarlos en el tema, pero no estaba exento de riesgo. De esta manera, comenzamos a trabajar con pistolas y fusiles de juguete.

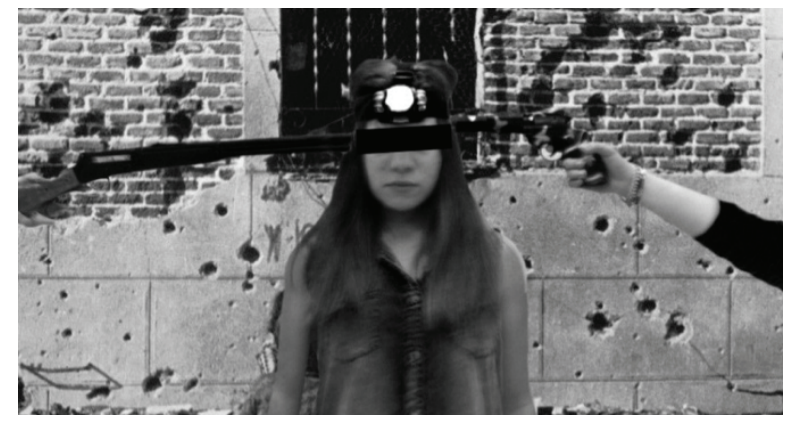

Figura 1. Imagen de "Sacrificio humano"

Pedimos a los alumnos que se relajaran mirando la pistola, que la tocaran y nos propusieran diversos movimientos y acciones con el objeto como protagonista. El trabajo se hizo de modo individual, pero también en grupos pequeños, a lo sumo de tres alumnos. De repente, sus propuestas empezaron a ser diamantes escénicos en bruto, sin tener los alumnos apenas conciencia de ello. Una de las propuestas de mayor impacto visual surgidas en el aula consistía en una especie de fusilamiento, llegó al montaje final y se convirtió en icono de la compañía. Es por todo ello crucial que el objeto seleccionado sea poderoso y no les deje indiferentes. Basándonos en los principios de Grotowski iremos después destilando las propuestas con cambios de intensidad, con pausas y tensiones físicas y cambios de velocidad. Ahí es crucial el uso de músicas y espacio sonoro que, como ya hemos señalado, tampoco debe dejarse para el final, sino que debe estar presente en el aula desde el inicio. El profesor debe llevar un conjunto de músicas evocadoras y útiles que acompañen los ejercicios y a su vez los realcen. El alumno debe convivir desde el inicio con ese espacio sonoro que nos va a ayudar a dirigirle en la distancia al marcarle los cambios de escena, los tiempos y las pausas. El espacio sonoro va a 
sustituir nuestra voz de director de escena, va a ser un mando a distancia que les va a marcar el tempo durante las actuaciones.

\section{LA MÚSICA Y EL ESPACIO SONORO EN EL PROCESO CREATIVO.}

La música adecuada va a convertir poco a poco un ejercicio básico en una escena en bruto. $\mathrm{Y}$ a su vez, va a aportar una dimensión emocional a la interpretación de nuestros alumnos. Les va a transportar a otra realidad y van a ver realzadas sus acciones. Sobre este tema, existen múltiples posibilidades. En nuestro caso, contábamos con la colaboración de dos alumnos que tocaban guitarra eléctrica y acústica y la batería. Disponíamos de una batería básica en el aula 6 de música. También fue crucial la selección de músicas emocionalmente impactantes debidamente alteradas en función de nuestros objetivo y (esto fue muy importante) mezcladas con ruidos mediante programas de edición de audio como Adobe Premiere, como la inclusión de sonidos de disparos. Así pudimos dar una dimensión aún más realista y emocionalmente potente a sus acciones. Los alumnos reaccionaron de manera entusiasta. Gracias al sonido y la tecnología, esas pistolas de juguete "sonaban". Sus acciones adquirían así un peso distinto, cobraban significado y tanta potencia como el uso de palabras.

\section{PROCEDIMIENTOS PARA LA FAMILIARIZACIÓN, COMPRENSIÓN Y MEMORIZACIÓN DEL TEXTO}

Poco a poco el alumno toma conciencia de que cada ejercicio, sonido, movimiento o acción tienen un fin. Hasta ahora no hemos requerido de la memorización de texto para la escena que se estaba construyendo.

Con un grupo de alumnos que van adentrándose en un nuevo territorio, empieza a entrar en juego la presentación de materiales relacionados con el tema y que pueden ir sembrando la cosecha de textos posteriores. Es importante introducir imágenes, documentos, vídeos de un modo interactivo y altamente visual mediante aplicaciones y programas como Keynote o Powerpoint. Con una escena aún sin palabras y en un estado emergente, con un alumnado cada vez más motivado sin dejar de estar algo extrañados por el método de trabajo en el aula, decidimos hacer una presentación en Keynote con imágenes de niños soldados y pequeñas frases, textos, relacionados con ellos. También llevamos a cabo un vídeo con fotos y música que llamamos CHILD SOLDIER mediante iMovie. Ese vídeo lo mostramos al grupo a través del iPad. Posteriormente este tipo de materiales los mostraríamos con un proyector conectado al iPad y a unos altavoces. Usaríamos la pared como pantalla. De este modo, transformamos el aula 6 de música en un aula audiovisual y tecnológicamente avanzada.

Las reacciones al material audiovisual fueron diversas, pero los alumnos las siguieron atentamente. Hablamos de un grupo con dificultades para seguir una clase tradicional y frontal. En primer lugar, muchas veces se sintieron conmovidos al ver personas de su edad en un contexto bélico. Se inspiraron para llevar a cabo 
acciones más complejas con las pistolas de juguete. Entendieron mejor el tema y al ver niños soldados de muchas épocas, comprendieron mejor la dimensión histórica del proyecto y su sentido de denuncia de una situación injusta. Muchos nos preguntaron por la tecnología usada en los materiales y algunos por las palabras que de vez en cuando aparecían. Eran casi todos textos extraídos de canciones que tratan el tema de la violencia, de intérpretes que van desde Madonna a Pet Shop Boys pasando por One Direction.

[...] Los audiovisuales me resultaron conmovedores, especialmente el referente al bullying (acoso escolar), me hizo recapacitar del mal trago que pasan algunos compañeros simplemente por ser diferentes. (Opinión de un alumno espectador)

En la segunda parte de esa clase, se repartió a cada alumno una imagen diferente en papel de todas las aparecidas en los audiovisuales. Les proponíamos después expresar sus emociones al respecto en el reverso de esa imagen. Sin darse cuenta fueron generando un cuerpo de texto sobre el tema. Esos textos nos los llevamos a casa para trabajarlos y seleccionar los más adecuados de cada alumno. En la siguiente clase los comentamos, repartimos de nuevo y les dimos a cada uno la selección que habíamos llevado a cabo de sus redacciones. Después les propusimos que seleccionaran su frase favorita de su propio texto. Les dejamos un tiempo en el aula para que la memorizaran. Lo hicieron.

Queríamos aclarar que durante estas dos sesiones, el espacio del aula seguía siendo el mismo: sin sillas en el espacio central, semiiluminado y con una música de relajación que invitara a la calma y la concentración.

El reto siguiente fue combinar su protoescena con acciones y movimientos con las pistolas y sus frases. Poco a poco y por grupos de tres se fueron formando escenas y, para su sorpresa, sus palabras encajaban muy bien con las acciones y el conjunto, incluida la música y los ruidos de disparos. Las fueron puliendo para decidir cuándo incluir cada elemento y sincronizarlo con la música y los disparos, fueron desarrollando sus propuestas hasta fijarlas en una escena final que pudiera repetirse de modo claro y preciso. El resultado llegó al escenario y se llamó "Sacrificio humano". Una de las escenas más impactantes del montaje.

\section{LA REALIZACIÓN DE LA PRIMERA ESCENA Y SU IMPACTO EN LA EVOLUCIÓN DEL GRUPO}

La realización de esta escena supuso un avance considerable en el grupo y en su confianza en el proyecto, el método y el profesor. De repente, y de un modo muy intuitivo, se vieron representando escenas con principio, desarrollo y final; escenas con movimientos, palabras, objetos, músicas y ruidos que coincidían con sus acciones. En ese momento del taller comenzaron a representar ante público un fragmento de lo que sería el proyecto futuro, dicho público estaba compuesto por 
sus compañeros de aula. Empezaron a analizar y debatir cada propuesta para mejorarla. Fueron actores y directores de escena sin darse cuenta.

El grado de satisfacción con la escena llevada a cabo fue muy alto. El grupo fue venciendo su escepticismo y comprendiendo el método de trabajo. Un factor destacable es que se sintieron autores de la propuesta: de las acciones, de las palabras, de la evolución de la escena. No lo sintieron como algo ajeno o impuesto. Empezaron a percibir nuestros ejercicios más como hojas de ruta que como escenas planificadas e impuestas. Fueron poco a poco sintiéndose partícipes de un proceso de creación colectiva y de un proyecto de teatro comunitario (Bidegain, 2011) y de la diversidad defendida por Jo Verrent (Verrent, 2013), que no distingue entre un teatro profesional y uno amateur por considerar que la calidad artística no es la maestría técnica sino una expresión original y diferente.

Este aspecto es también muy relevante a la hora de comprender los buenos resultados de la asignatura: el alumnado tenía un objetivo común, que superaba sus diversas individualidades. El objetivo común fue marcando el territorio e hizo que se relajaran los sentimientos de competitividad que podían florecer en algún momento. Por otro lado, la asignatura estaba sujeta a una evaluación y cada alumno recibía una nota numérica trimestre tras trimestre. Este factor en nuestro caso no actuó como un elemento de presión o desmotivador, ya que desde el inicio aclaramos que íbamos a valorar lo procedimental y el compromiso con el proyecto. Lo que sería evaluado sería el trabajo en el aula, sin tener que someter al alumnado a pruebas objetivas o exámenes. También aclaramos que no íbamos a poner notas basadas en una subjetiva calidad artística de los resultados, sino en el esfuerzo y compromiso en el proceso de trabajo. Aproximadamente cada dos semanas el alumno recibía una nota de clase que le era comunicada y explicada para que pudiera mejorarla. Esta estrategia también tuvo una repercusión muy positiva en la prevención del absentismo en la materia. La optativa de Teatro había tenido un grave problema en cursos anteriores con la falta de asistencia a clase. Este método de evaluación, el uso de una metodología más instrumental y arriesgada y, muy especialmente, el interés despertado en el alumno por la asignatura provocaron un índice de asistencia elevadísimo, así como una reducción en el número de partes disciplinarios en $3 \mathrm{ESO}$ y aquí debemos mencionar que no se ha puesto ningún parte entre los alumnos durante el transcurso de la materia.

Tras la realización de la primera escena en bruto, los alumnos se mostraron más abiertos al aprendizaje de algún texto de memoria de cosecha ajena. En ese momento, consultamos nuestro archivo documental para buscar frases de especial impacto, breves y que pudieran atraparles. Fragmentamos poemas relacionados con el tema. Y sobre todo utilizamos letras de canciones, siendo éste otro de los aspectos más innovadores del trabajo. Los versos de canciones se les presentaban fragmentados. La rima y su lenguaje directo, pegadizo, favorecían la memorización. Repartíamos a cada alumno solo un par de versos para no agobiarles con el volumen de texto para aprender. En ningún momento 
revelábamos las fuentes, sólo al final del proceso y para ayudarles a recordar sus frases. Los fragmentos poseían una fuerza increíble, rozando los lemas publicitarios. Desde una perspectiva contemporánea, se abre así la posibilidad de utilizar textos infinitos, de múltiples fuentes, literarias o no, e incluso la posibilidad de que el alumno proponga textos. Los fragmentos se aprendieron de memoria en el aula. Debemos insistir en este aspecto porque muchas veces un taller de teatro con un grupo de estas características se puede venir abajo porque el profesor les encarga aprender esos textos en casa. Es un error. Hay que dedicar un tiempo en la clase, enseñarles trucos mnemotécnicos, estrategias, crear un ambiente de relajación y concentración en el aula. Los alumnos se van así de la clase con los fragmentos aprendidos y preparados para montar escenas. Esas escenas se basaron de nuevo en el método biomecánico de interacción con objetos y espacios: sillas, telas, el cuerpo de los compañeros, linternas, ropa militar,velas, etc.

\section{LA INTRODUCCIÓN DE LA TECNOLOGÍA, INTERNET Y LOS MATERIALES AUDIOVISUALES PARA CONVERTIR EL AULA EN ESPACIO GLOBAL}

Durante todo ese proceso, iniciamos un trámite legal y administrativo para que los alumnos tuvieran una autorización de los padres o tutores que nos permitiera fotografiarles, grabarles en audio y vídeo y poder usar ese material con fines didácticos. En este proyecto decidimos introducir una novedad que era el uso de las redes sociales como vía de comunicación con el alumno, pero también como promoción del proyecto. Se trataba de una apuesta diferente en el marco de la enseñanza reglada en Secundaria, porque con mucha frecuencia se emplean plataformas meramente educativas como Moodle o Educamadrid, plataformas cerradas y que el alumno ve como algo aparte y propio del marco educativo. Nuestra apuesta era infiltrarnos en sus círculos, en sus redes, formar parte del día a día de su teléfono móvil u ordenador personal. Las autorizaciones fueron llegando y empezamos a generar la producción de un material audiovisual único que dio otra dimensión al proyecto y que tiene mucho que ver con el grado de responsabilidad y compromiso de los alumnos.

Habitualmente, en teatro escolar se ha empezado a usar la tecnología con cierta lentitud. Muchas veces se relega a la grabación de la actuación de fin de curso o de algún ensayo. La propuesta que hemos desarrollado en este proyecto iba más allá: la grabación y fotografía de múltiples ensayos y ejercicios que ese mismo día eran compartidos en internet a través de redes como Twitter y Facebook o canales de vídeo como Youtube o Vimeo. A su vez, el departamento de Lengua del instituto tenía un blog en Wordpress que fue utilizado como plataforma pública, supliendo el carácter privado que ofrecían los perfiles de las redes sociales.

[...] En el blog he entrado pocas veces, pero sí que seguía el Twitter y el Facebook del grupo de teatro, me gustaba ver las fotografías y vídeos que se "colgaban", aun 
así no me gustaba intervenir por vergüenza y para conservar mi privacidad (Opinión de alumno de teatro).

A medida que las autorizaciones fueron llegando, fuimos agregando y siguiendo a nuestros alumnos y a profesores o especialistas en la materia. A su vez, los alumnos fueron familiarizándose con la presencia de cámaras y dispositivos que les grababan en vídeo y les fotografiaban. De esas grabaciones fuimos seleccionando material para compartir.

Gracias a los avances tecnológicos, una foto o una breve escena de vídeo pueden tener unas transformaciones y repercusiones ilimitadas. El material es casi infinito. Nos familiarizamos con aplicaciones y programas básicos o más complejos de manipulación fotográfica y edición en vídeo como Instagram, 101 cámaras, Adobe Premiere, Adobe Photoshop o iMovie. Utilizamos recursos del marketing para crear una imagen corporativa para el proyecto y diseñar una campaña publicitaria local y global. Decidimos un nombre para la compañía que fue el del instituto "Al Satt", étimo en árabe de Algete, con un logo que era la palabra en castellano y árabe. Comenzamos a manipular fotos de especial impacto visual salidas del trabajo en el aula 6 con los alumnos: las filtramos, las pasamos a blanco y negro, las ampliamos hasta volverlas irreconocibles, o las cambiamos de fondo situando a los alumnos en un paisaje histórico de guerra. Todo ese material era mostrado a los alumnos en el aula y colgado en internet rápidamente. La reacción del alumnado fue altamente satisfactoria y muy motivadora. Empezaron a sentirse parte de un proyecto que superaba las dimensiones del aula 6 y que estaba a punto de desembarcar en el propio instituto.

Nos decidimos por varias imágenes muy impactantes para imprimir en forma de carteles publicitarios. Empezamos a poner los carteles en el propio instituto generando un efecto de sorpresa en los alumnos. Teatro empezaba a buscar su público.

Los fragmentos de vídeos de escenas en formación empezaban a aparecer en internet despertando la curiosidad del espectador, en ocasiones a modo de trailers cinematográficos. Del mismo modo, fuimos informando de los avances del grupo online. Toda esta red de difusión tuvo a su vez otra plataforma impagable que fue la de CaixaEscena. Semana tras semana íbamos compartiendo nuestros avances con ellos en sus diversos foros y nos fuimos ganando poco a poco un nombre en el certamen.

El alumno de Teatro empezó a ver que su trabajo tenía una dimensión global que le obligaba a responsabilizarse aún más con el proyecto. Todo ello repercutió en una mejora del trabajo en los ensayos. Cada vez se inclinaron más por el aprendizaje de textos de memoria ajenos o propios, se fueron mostrando más flexibles para la producción de escenas e incluso empezaron a dedicar recreos y séptimas horas a la mejora del proyecto escénico, luchando por obtener un mayor protagonismo en escena. 
En alguna ocasión las redes sirvieron como modo de convocatoria, intercambio público y privado e incluso dirección y guía a distancia. Por otro lado, queremos insistir aquí en que el alumno empieza a observar el trabajo del instituto en la optativa de Teatro no como algo ajeno a su mundo, sino que se inmiscuye en él, se infiltra, comparte y retuitea. No es un espacio virtual aparte, como Moodle o Educamadrid, sino que está en los circuitos en los que se mueve el alumno. Empieza a no haber límites en los lugares de aprendizaje online. Una descripción más detallada sobre el trabajo técnico con internet, medios audiovisuales y redes sociales se encuentra recogido en publicaciones previas (López Velasco, 2013).

En menos de dos meses el grupo había conseguido producir un conjunto de unas ocho escenas muy bien engarzadas entre sí mediante estudiadas transiciones, músicas y efectos sonoros. Un ensayo fundamental para este avance fue el de Halloween. Los alumnos llegaron disfrazados ese día al centro y se pintaron la cara con pinturas de guerra. Nosotros aportamos un fondo de vestuario bélico de nuestra propiedad y provocamos un ambiente en clase a caballo entre la fiesta, la rave y el trabajo escénico. Mediante el uso de músicas muy potentes, de acciones básicas en un grupo disfrazado y de repetición de sus frases, el grupo generó sin darse cuenta casi una performance en el aula. Esa clase fue grabada y fotografiada dando lugar a un copioso material que provocó una subida de visitas en internet. Hicimos varios vídeos con ese material y numerosas fotos y carteles, también compartidos en CaixaEscena.

Para dar otra dimensión al aprendizaje de los textos comenzamos a grabar sus voces recitándolos y alterándolas mediante aplicaciones y programas para generar música electrónica tales como GarageBand, Logic Pro X, Cubase o Algoriddim. De repente, vieron sus voces transformadas formando parte de un marasmo electrónico que llegaría a formar parte del espacio sonoro final. Todo este material audiovisual colgado en internet les servía para corregirse y mejorar y como incentivo para la memorización de sus textos y acciones.

El grupo empezó a practicar también con música en directo hecha por y para las escenas producidas. Del mismo modo, los alumnos con habilidades beneficiosas para el grupo fueron proponiendo escenas donde poder introducirlas: canciones cantadas por ellos, escenas con texto en inglés, trucos de magia, bailes de hip-hop y ejercicios de gimnasia rítmica. Comenzaron a comprender que el método y su flexibilidad favorecían la introducción de novedades y propuestas por parte de cada miembro del grupo.

\section{PRIMERAS ACTUACIONES Y ENFRENTAMIENTO CON EL PÚBLICO}

A esas alturas del primer trimestre, a mediados de noviembre, tomamos dos decisiones arriesgadas: presentar todo lo que llevábamos hecho en una función de Navidad el 20 de diciembre de 2012 y hacernos con las riendas de la Gala Benéfica anual del instituto. La profesora del departamento de Lengua Silvia Agosto había 
visto la necesidad de cambiar el concepto de gala benéfica del centro en favor de un montaje integrado y coherente con objetivos comunes, sin pausas y que presentara una unidad temática y narrativa. Propuso su obra "Caminos de hierro" como vehículo para recibir las habilidades artísticas de un grupo de alumnos a los que Teatro ya no daba de sí para integrar y continuar el trabajo de CHILD SOLDIER. La gala estaría dividida en dos turnos y adaptada a la edad del público: "Caminos de hierro" para el primer ciclo de la ESO y CHILD SOLDIER para el resto. A su vez, actuaríamos por la tarde para padres y amigos. De este modo, la gala tendría una supervisión activa del profesorado y los participantes estarían sujetos a un proyecto común e integrado para convertir la gala en algo más educativo, dinámico y coherente. La idea se fue abriendo paso, no sin dificultades, y cristalizó el 15 de mayo de 2013 en una Quinta Gala Benéfica renovada e histórica.

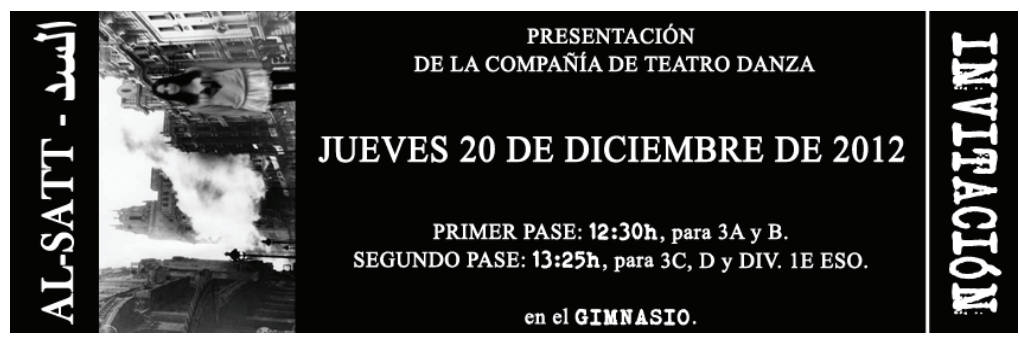

Figura 2. Entrada de la primera representación ante público

La otra decisión era nuestra presentación de Teatro el 20 de diciembre, con todo lo que llevábamos, en una especie de performance o ensayo general con público. El metraje por aquel entonces era de una media hora larga. Solicitamos el flamante gimnasio del centro para llevar a cabo el montaje. Situamos en él un equipo de música conectado al iPad, los instrumentos de los músicos en directo, proyecciones de vídeo en las paredes del gimnasio, y cámaras para grabar el acontecimiento. Iniciamos toda una campaña de promoción entre los grupos escogidos para asistir como público al evento: carteles y entradas dadas a cada alumno asistente que imitaban las entradas de los conciertos.

Durante la preparación de esas actuaciones del 20 de diciembre de 2012, los alumnos se enfrentaron a su miedo escénico y a las inseguridades sobre la falta de historia lineal en el montaje que pudiera dificultar su comprensión. Esta duda suele surgir cuando aplicamos pautas de creación escénica contemporánea al teatro escolar. Por un lado, los alumnos suelen identificar teatro con la narración en escena de una historia. Por otro, desconocen la tradición de la Vanguardia histórica y los orígenes rituales del teatro. A su vez, con frecuencia calibran la maestría o calidad de un proyecto en función de su calidad técnica, no de su diferencia, singularidad, originalidad o naturaleza única, tal y como defiende la directora 
teatral Jo Verrent (Verrent, 2013) para este tipo de proyectos. Hay que hacer con ellos todo un ejercicio de terapia para insuflarles seguridad y cambiar su perspectiva. Asimismo, debemos preparar al público para valorar lo que va a presenciar.

No queremos aquí negar el papel que juega en este método de trabajo lo fragmentado como modo de expresión artística, e incluso lo simbólico. Muchas veces para el alumno de ESO se trata de un salto al vacío. Por todo ello, muchas veces utilizamos dos recursos que les apoyen y que guíen al público: la utilización esporádica de un narrador que ya tenía "Historia de un soldado" de Stravinsky y los audiovisuales que aclaren el tema. De este modo, ensayamos con el alumno que tocaba la batería un monólogo que explicaba el tema del niño soldado a lo largo de la historia junto con un audiovisual ilustrativo y un potente audiovisual que abría el montaje del 20 de diciembre.

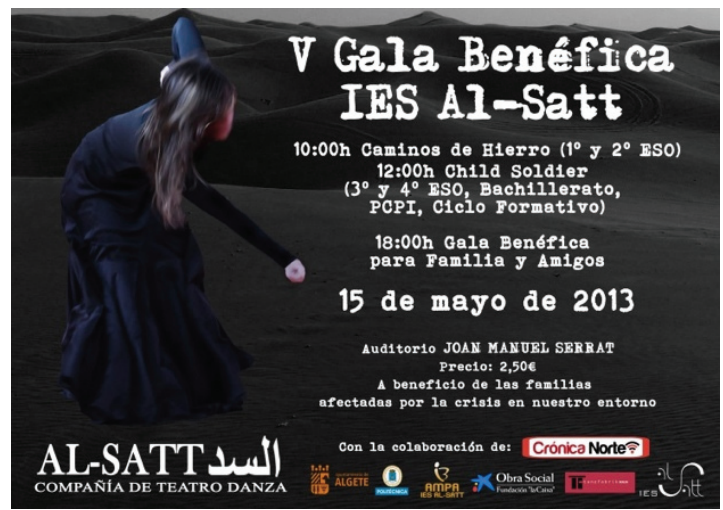

Figura 3. Cartel de la Gala Benéfica

La función de Navidad tenía también como objetivo entrenar al alumno en el contacto con el público. Sobre todo, para los que carecían de experiencia previa. Comenzamos a hacerlo gracias a ensayos con público en el gimnasio el 19 de diciembre. Hubo grupos muy receptivos y que iban preparados para la experiencia $\mathrm{y}$, desafortunadamente, algún grupo que no. Tuvimos que superar algún trance traumático de cara a las exitosas actuaciones del día 20. Alguna minoritaria reacción negativa que hizo mucho daño a algún alumno sin experiencia anterior. La base de estas minoritarias reacciones negativas fue la falta de tiempo para preparar al público perteneciente a algún grupo de alumnos. En Teatro no solo hacemos una labor con los alumnos que están en el escenario, sino también con los que forman parte del público. Nuestro trabajo es también formar al público que acude a ver teatro escolar.

A principios del mes de diciembre nos llegó una noticia que generó más confianza en el alumno: CaixaEscena nos había seleccionado para participar en los 
Encuentros CaixaEscena en Alcalá de Henares a principios de marzo de 2013. La selección incluía recibir talleres por parte de destacados profesionales del gremio y la presentación de un fragmento del proyecto, de una media hora, en el corral de comedias de Alcalá. La noticia motivó enormemente al grupo y contribuyó a la autoestima de sus miembros.

El trabajo del 20 de diciembre fue cuidadosamente grabado y fotografiado por Juan Pedro López Velasco, dando lugar a una estrecha colaboración con la Universidad Politécnica de Madrid que ha financiado la impresión del material gráfico del proyecto e iniciado una labor investigadora con el instituto Al Satt. La existencia de una fecha para una actuación suele incidir de un modo positivo en el trabajo del alumno. El material audiovisual fue cuidadosamente montado en un DVD con subtítulos en castellano e inglés que sería usado por el alumno en el 2013 como libro de texto interactivo. A la vuelta de vacaciones, los alumnos habían visto numerosas y excelentes fotos del evento en internet y volvieron con una elevada conciencia sobre la importancia del proyecto, lo que generó una cierta competitividad entre ellos. El DVD fue visto por los alumnos en clase y convenientemente debatido con vistas a cimentar el trabajo en el 2013.

\section{EVOLUCIÓN DEL GRUPO HACIA LA CONSOLIDACIÓN Y EL ÉXITO EN EL MARCO DEL TEATRO ESCOLAR.}

Sobre estas bases y métodos establecidos fuimos evolucionando hasta conseguir la clausura de CaixaEscena en Alcalá un 3 de marzo de 2013 y una Quinta Gala Benéfica histórica para el centro un 15 de mayo con el uso de proyecciones en escena sobre una pantalla de $8 \times 4$ metros. La gala batió un récord de asistencia y recaudación.

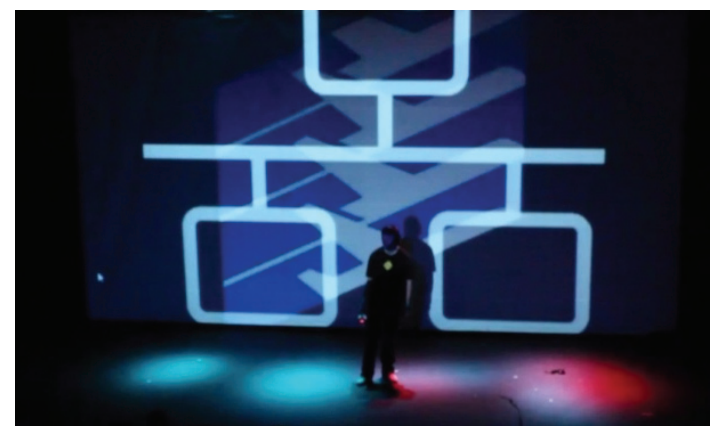

Figura 4. Escena del montaje de la Gala Benéfica

Casi todo el material se encuentra en internet, incluida la actuación en Alcalá y la Gala Benéfica. Los canales de Vimeo y Youtube superan ya las 2000 visitas y más de 3500 minutos de visión. El proyecto tuvo consecuencias en prensa online y en papel en numerosos medios (Europapress, La Vanguardia, El diario de Alcalá, 
La Voz de Algete y Crónica Norte) y los perfiles de Facebook y Twitter se han convertido en un campo de referencia en el trabajo del instituto. El blog ha tenido a su vez una función constante. El proyecto se ha presentado ya en dos congresos internacionales, en las $V$ Jornadas sobre enseñanza de las artes escénicas e inclusión social en Barcelona el 20 y 21 de marzo de 2013, y en la Networked and Electronic Socialmedia Summit en Nantes a finales de octubre de 2013. Se trata, sin ningún género de dudas, del proyecto más difundido en la historia del centro.

\section{ENCUESTA FINAL COMO MÉTODO DE OBTENER LAS IMPRESIONES DEL ALUMNO}

Una vez terminado el curso, en las últimas clases dedicadas a la asignatura, se decidió abordar una encuesta que reflejara por escrito las diversas impresiones del alumno con respecto a la metodología y su interacción con el montaje realizado.

La encuesta consistía en una serie de preguntas con varias posibles respuestas, de completar con frases cortas y únicamente al final se destinaba un espacio para escribir libremente, de manera que la encuesta era muy guiada para facilitar la concreción de las respuestas y evitar la dispersión del alumno. En todo momento se empleó un lenguaje cercano que ellos pudieran comprender y, durante la realización de la encuesta, se contestó a todas sus preguntas sobre cualquier duda que pudiera surgir. Posteriormente, las encuestas completas fueron procesadas y evaluadas, extrayendo estadísticas que permitieran evaluar el proyecto utilizando como base las opiniones de sus principales protagonistas. De esta forma, pudimos contar con características cualitativas y cuantitativas, que nos permitieron tener una visión global de conjunto y corroborar por escrito lo que se había constatado únicamente de manera oral y mediante impresiones subjetivas. 


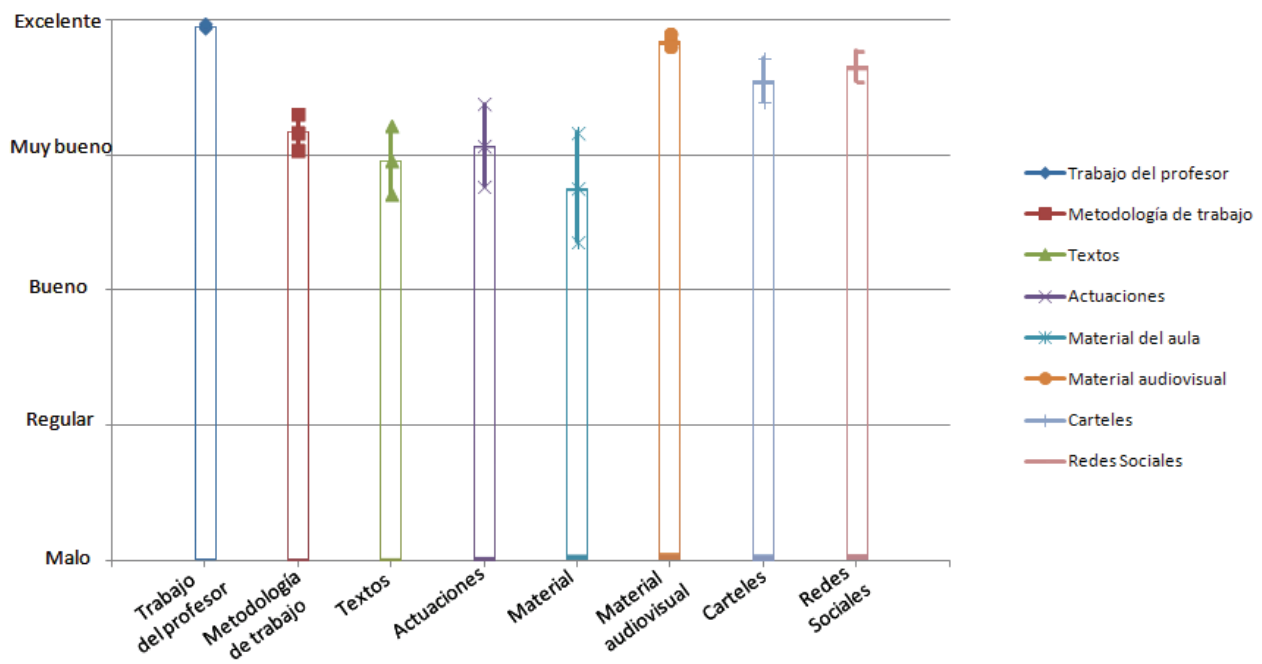

Figura 5. Evaluación (media e intervalo de confianza) de distintos factores del proyecto

En primer lugar, los alumnos fueron preguntados por la calidad del montaje y los medios (Figura 5), para corroborar su satisfacción general con el proyecto, recibiendo elogiosos resultados. Los alumnos destacaron la calidad del trabajo del profesor, así como la utilización de material audiovisual, el cual calificaron de impecable. Las redes sociales y los carteles fueron valoradas también positivamente. Otros factores que fueron valorados pero en menor medida son la metodología de trabajo y textos, debido a una falta de compresión de los mismos, los cuales calificaron de raros o extraños, en multitud de ocasiones. En la inferior valoración de las actuaciones se puede observar el reflejo de una cierta "mea culpa", ya que la mayoría consideraba que se podrían haber mejorado con un mayor esfuerzo de los alumnos en el escenario, no tanto por la mejora técnica y el material audiovisual, que recibió muy buena acogida.

Se preguntó a los alumnos por diferentes aspectos para ver en qué grado consideraban que había sido para ellos un importante factor motivacional a la hora de la realización del proyecto. Los resultados se recogen en la siguiente gráfica. En primer lugar, se puede ver cómo el trabajo del profesor es el factor motivacional más importante, así como las actuaciones (Caixa Escena, la Gala Benéfica), que también aparecen bien puntuados. También reciben buena acogido los medios técnicos, entre ellos los carteles, las redes sociales, los vídeos y las fotografías, los cuales despiertan su atención debido a la innovación que suponen en el entorno del teatro escolar, mientras que el apoyo de padres y alumnos queda relegado a segundo plano, reflejando el poco interés del proyecto en el entorno motivador del alumno, de cara a sus familiares. 


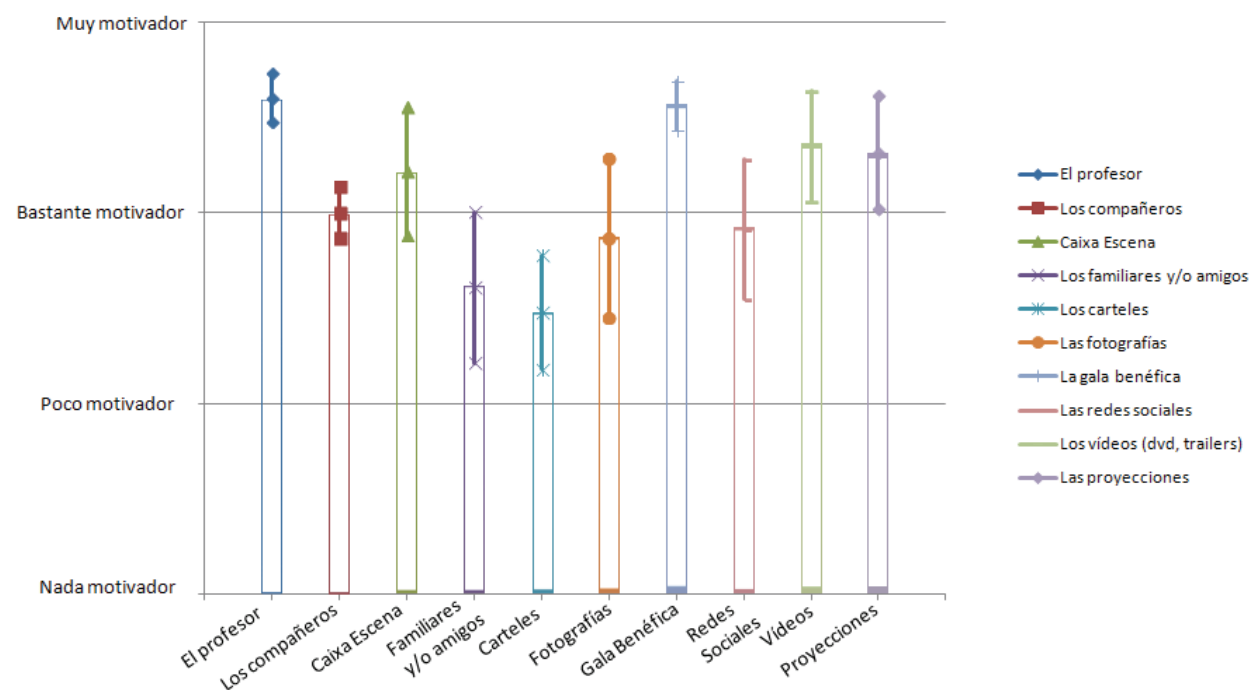

Figura 6. Valoración de los factores motivacionales (media e intervalo de confianza)

Otra de las preguntas de gran importancia, que refleja la satisfacción de los alumnos con el proyecto, es si les gustaría dedicarse al teatro en el futuro, a lo que la mayoría contestó que les gustaría como afición, incluso algunos se atrevieron a decir que incluso desearían hacerlo de manera profesional.

Entre las opiniones de los alumnos recogidas al final de la encuesta, son en su mayoría satisfactorias, felicitando al profesor por su trabajo y destacando el compañerismo y el clima de trabajo que se ha generado.

[...] Se fomentó el compañerismo y mucha gente perdimos la timidez. Ha sido un trabajo conjunto, se han escuchado nuestras ideas y sugerencias, y muchas se han puesto en escena. La metodología la encontré rara, pero el tema de la violencia y las armas me resultó muy atractivo. (Opinión de un alumno del proyecto)

\section{CONCLUSIONES}

El proyecto aquí presentado es resultado de un método de trabajo, que se ha ido cimentando a lo largo de la experiencia de años de labor en el marco de la enseñanza, el teatro y la danza profesionales y alternativos, así como el teatro aplicado a fines didácticos. Se trata de la puesta en práctica de la interacción de diversas visiones del hecho escénico y el educativo que entroncan con la aplicación de manifestaciones artísticas contemporáneas al marco del aula de secundaria. La experiencia aquí relatada vuelve a demostrar que la escena contemporánea no se halla alejada del alumno de ESO, sino que por el contrario es la idónea como modo de trabajo, como visión artística, ideológica y educativa del hecho docente y como resultado gratificante en escena. 
Partiendo de este principio, el espacio (físico y sonoro), las dinámicas y los ejercicios en la clase están sujetos a una metodología más flexible y abierta para la que el proceso creativo es más un descubrimiento que un resultado fijado en un texto verbal desde el inicio. Desde ese punto de vista, el trabajo colectivo del grupo en el aula sitúa al profesor más como un orientador que como un director férreo que sólo busca la materialización de un texto fijado de ante mano.

Las actividades programadas en el aula dan más importancia al tema y los procedimientos creativos escénicos que al texto verbal. Y cuando éste comienza a aparecer en escena, se sitúa en el proceso de aprendizaje de una manera más comprensiva, adaptada y dinámica que avanza en función de las características de cada alumno.

El proyecto entrena a los alumnos como autores de una manifestación artística contemporánea, pero también como espectadores. Les libera de prejuicios que asocian el teatro con la narración de una historia y la presentación de un mundo muy definido y les pone en contacto con expresiones artísticas más evocadoras, fragmentadas, simbólicas y poéticas. De este modo, el alumno actor y el alumno espectador se familiarizan con la escena actual surgida de la Vanguardia histórica.

A su vez, la comunidad educativa aprende a observar el teatro escolar dentro del marco del teatro comunitario actual buscando otros parámetros para evaluar su calidad, parámetros no basados en la maestría técnica, sino en su diferencia, singularidad, originalidad y naturaleza única. Por todo ello, los miembros de la comunidad educativa desarrollan un sentido más amplio y actual del hecho artístico no como una expresión de excelencia técnica, sino como el descubrimiento excelente de un mundo propio y único.

La tecnología, internet y las redes sociales hacen su aparición en el aula no como adornos durante el proceso, sino como columnas vertebrales fundamentales en su desarrollo. Implican la grabación de vídeo y audio desde casi el inicio del proyecto y la fotografía del trabajo. Van a generar un material audiovisual que sirve como recurso didáctico para el aula al permitir al alumno observarse y mejorar. Van a convertir el espacio del aula en un marco global que se va a inmiscuir en las redes sociales usadas por los alumnos aumentando su interés y motivación. Va a contribuir a la creación de una imagen corporativa del proyecto que, inspirándose en los principios del marketing, deje su huella en el centro y en internet.

Con la llegada de internet al aula de Teatro, quedan abolidas las jerarquías entre asignaturas y entidades de control educativo. De repente, cualquier proyecto, cualquier alumno o profesor pueden reclamar un poder hasta ese momento no ostentado. El aula se hace global e inteligente. Este es un principio de no retorno. El aula global e inteligente va a suponer una revolución en la enseñanza que hasta la fecha conocemos. No es un aula dependiente de la visión de un equipo directivo concreto, de un claustro o de un grupo de alumnos; es un aula abierta a la democratización del conocimiento, el arte y la enseñanza; es un aula que va a reclamar su derecho a participar y decidir gracias a su comunidad física y virtual; es un aula que va a poder crear su propio 
universo, sus decisiones y manifestaciones y que se va a volver más resistente a las jerarquías; es un aula que mira hacia el futuro y dialoga con otros proyectos globales; es un aula abierta al mundo.

\section{AGRADECIMIENTOS}

Queremos agradecer aquí la colaboración de la Universidad Politécnica de Madrid y del IES AL SATT por su apoyo, especialmente a la profesora Silvia Eva Agosto por su trabajo durante el proceso creativo. También a la Fundación La Caixa por su ayuda a través del programa CaixaEscena. A los medios de prensa citados en el artículo y al Ayuntamiento de Algete.

Para más información sobre el proyecto en las redes sociales: Twitter: @AlSattteatro; Facebook: alsatt.teatrodanza; Blog: alsattalgete.wordpress.com; Canal de YouTube: Alsattteatrodanza; Email:alsattteatrodanza@gmail.com; Website: www.alsattteatrodanza.tk

\section{BIBLIOGRAFÍA}

BARBA, Eugenio (1992): La canoa de papel. Colección Escenología. México, 1992.

BARBA, Eugenio (1986). Más allá de las islas flotantes. Colección Escenología. México, 1986.

BIDEGAIN, Marcela (2011). ¿Qué es el Teatro comunitario? Categorías para la definición del fenómeno cultural. Revista Anagnórisis, Junio 2011. Se puede encontrar en el siguiente enlace: http://www.anagnorisis.es/pdfs/Testimonioteatro_comunitario.pdf

GROTOWSKI, Jerzy (1981): Teatro de laboratorio, Barcelona, Tusquets, 1981. Para conocer mejor el método de trabajo llamado biomecánica.

IANANTOUNI, Stella (2009): Hatha yoga, Barcelona, Albatros, 2009. Para iniciarse en las técnicas del hatha yoga.

LÓPEZ VELASCO, J. P., BALLESTEROS FERNÁNDEZ, J. P., JIMÉNEZ BERMEJO, D., \& MENENDEZ GARCIA, J. M. (2013). Impact of new technologies and social networks on a secondary education theatre project. Nem Summit 2013 Proceedings, 111-116.

MIGNOLO, Walter. D. (2003): Historias locales/diseños globales: colonialidad, conocimientos subalternos y pensamiento fronterizo (Vol. 18). Ediciones Akal.

OIDA, Yoshi (2010): Los trucos del actor, Barcelona, Alba, 2010. Guía para buscar inspiración para ejercicios en el taller de Teatro.

PATTERSON, Jim; MCKENNA-CROOK, Donna; SWICK, Mellissa (2006): Theatre in the Secondary School Classroom: Methods and Strategies for the Beginning Teacher. Editorial Heinemann.

VERRENT, Jo. (2013): Take off your glasses and really see what are you looking at. Artículo que se puede encontrar en su página web: Believing that 'different' is delicious not divergent (http://www.joverrent.com/)

WATSON, Ian (1999) Hacia un tercer teatro, Ciudad Real, Ñaque, 1999. 